\title{
Demographic dividend, a window of opportunity for development: Implications for South-South cooperation
}

\author{
Selina F. Esantsi
}

Population Council

Follow this and additional works at: https://knowledgecommons.popcouncil.org/departments_sbsr-rh

Part of the Community-Based Research Commons, Demography, Population, and Ecology Commons, Family, Life Course, and Society Commons, International Public Health Commons, and the Quantitative, Qualitative, Comparative, and Historical Methodologies Commons How does access to this work benefit you? Let us know!

\section{Recommended Citation}

Esantsi, Selina F. 2013. "Demographic dividend, a window of opportunity for development: Implications for South-South cooperation," presentation at the Inter-Ministerial Conference on South-South Cooperation in Post ICPD and MDGs, Beijing, China, 22 October. 


\title{
Demographic Dividend, A Window of Opportunity for Development: I mplications for South-South Cooperation
}

\author{
Selina F. Esantsi \\ Inter-Ministerial Conference on "South-South \\ Cooperation in Post ICPD and MDGs" \\ Beijing, China \\ October 22, 2013 \\ (2) Population Council
}




\section{Outline of Presentation}

- Introduction

- Age Structure

- Country case studies

- Opportunities to earn the dividend

- Role of governments

- South-South cooperation

- Conclusion 


\section{DEMOGRAPHI C DI VI DEND}

- Accelerated economic growth associated with changes in the population age structure; specifically having more working age population relative to dependent population.

- Promoted by demographic transition

- Changing age structure presents an opportunity to harness dividend

- Key pre-cursors to realizing the dividend ; sound socio-economic policies; investments in health (including FP), education, governance, labour and job creation, etc. 


\section{Population - Age structure (1)}

\section{$\%$ Distribution of the World's Population by Age Groups}

\section{(Medium Variant)}

\begin{tabular}{|c|c|c|c|c|c|c|}
\hline \multicolumn{4}{|c|}{2013} & \multicolumn{3}{|c|}{2050} \\
\hline & $0-14$ & 15-59 & $60+$ & $0-14$ & $15-59$ & $60+$ \\
\hline World & 26 & 62 & 13.7 & 21 & 58 & 25.1 \\
\hline Africa & 41 & 54 & 5.9 & 32 & 59 & 9.8 \\
\hline Asia & 25 & 64 & 12.3 & 18 & 58 & 28.3 \\
\hline Europe & 16 & 62 & 27.5 & 15 & 51 & 43.5 \\
\hline $\begin{array}{l}\text { L. A. \& } \\
\text { Caribbean }\end{array}$ & 27 & 63 & 12.6 & 18 & 57 & 30.7 \\
\hline N. America & 19 & 61 & 23.7 & 18 & 54 & 35.1 \\
\hline Oceania & 24 & 60 & 18.9 & 20 & 56 & 29.2 \\
\hline Ghana & 38.5 & 56.2 & 5.9 & 27.5 & 62 & 11.2 \\
\hline Thailand & 18.2 & 67.3 & 16.4 & 12.5 & 50 & 47.5 \\
\hline
\end{tabular}




\section{Population - Age Structure (2)}
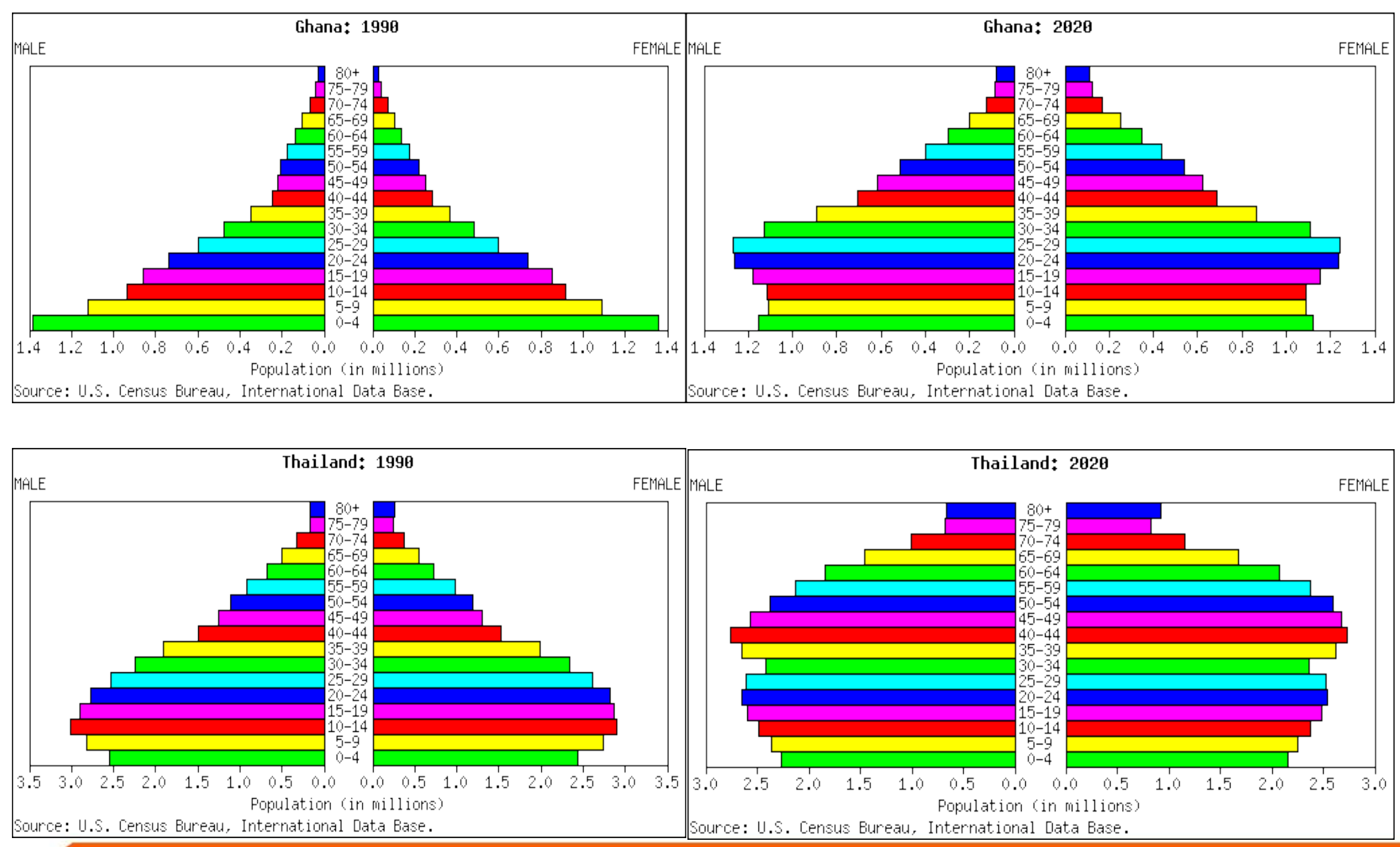


\section{Population - Age Structure (3)}

\section{Two diverging paths}

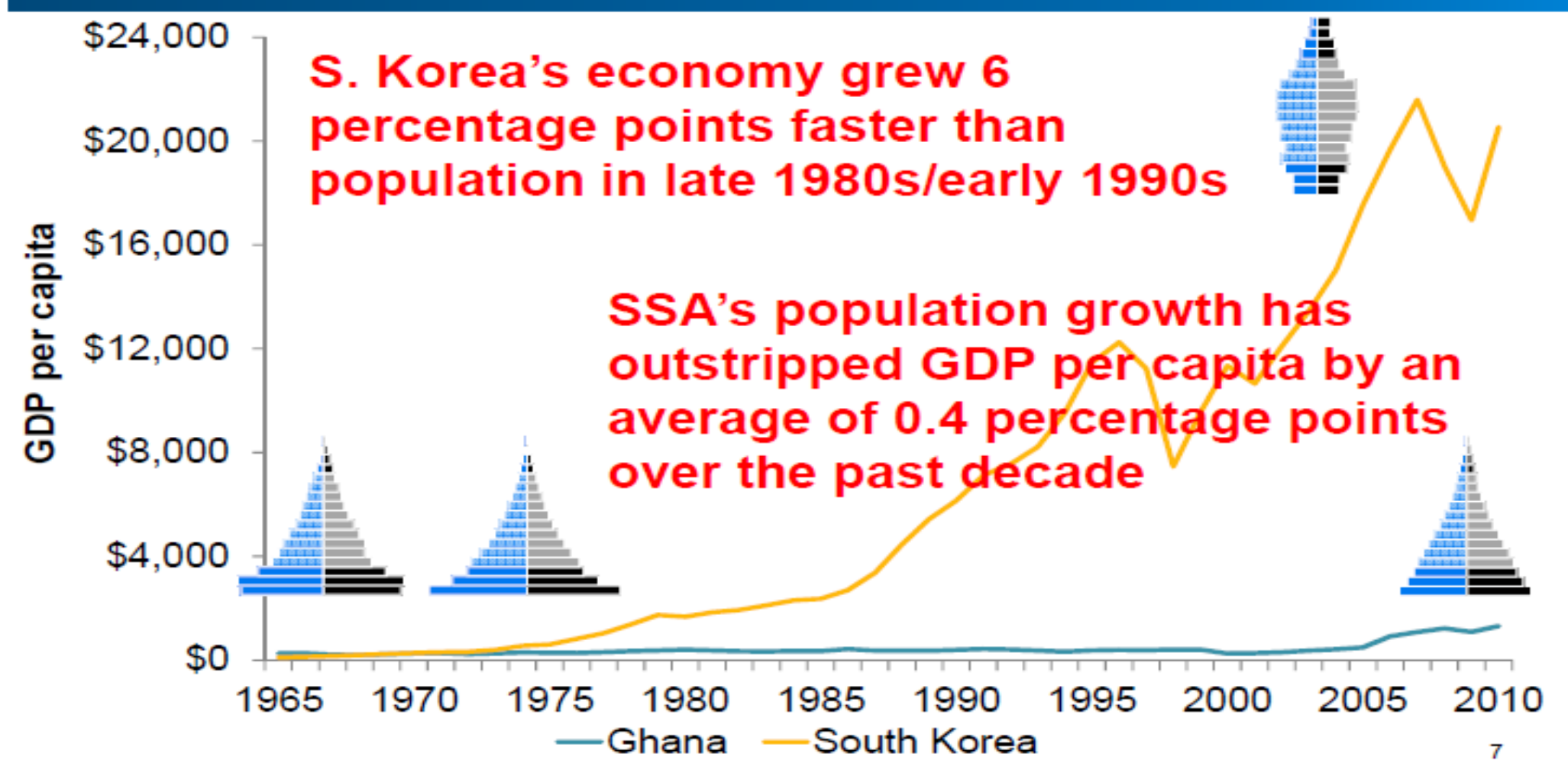




\section{Case Study (1)}

The Republic of Korea:

- Birth rate fell in the mid-1960s,

- Funds previously allocated for basic education were used to improve the quality of education at higher levels

- Overall, this improved the ratio of productive workers to dependents in the population 


\section{Case Study (2)}

\section{Ghana:}

- Stalled fertility decline

- Low job creation

- Limited quality higher education

- Limited employable skills 


\section{What worked in East Asia}

- Expanding access to FP

- Emphasis on education

(especially secondary+)

- High savings rates

- Secure financial system

- Openness to trade

- Flexible labor market 


\section{Opportunities to Earn Dividend (1)}

GNI per Capita

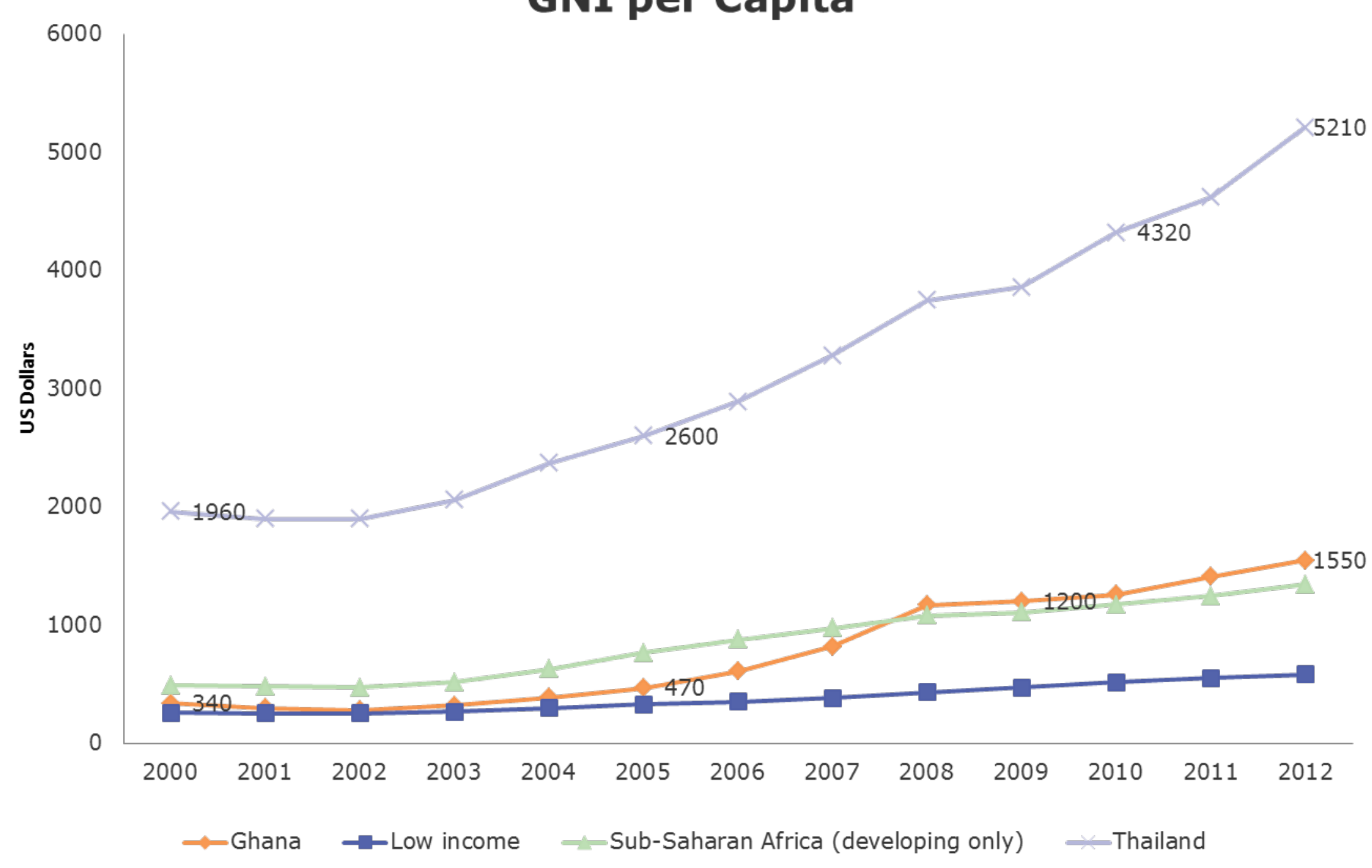




\section{Opportunities to Earn Dividend (2)}

\section{Annual Population Growth Rate (\% )}

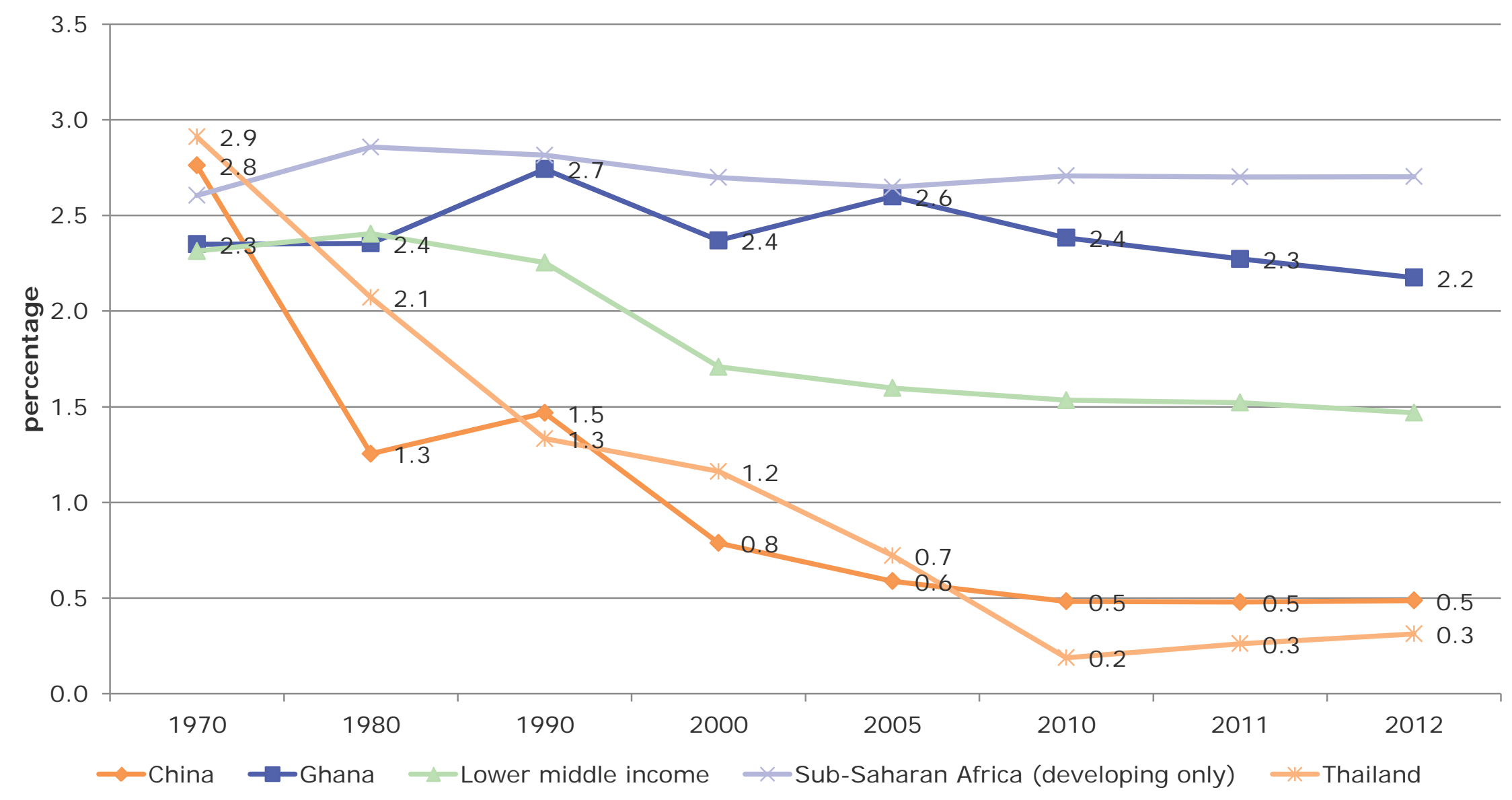




\section{Opportunities to Earn Dividend (3)}

Age Dependency Ratio

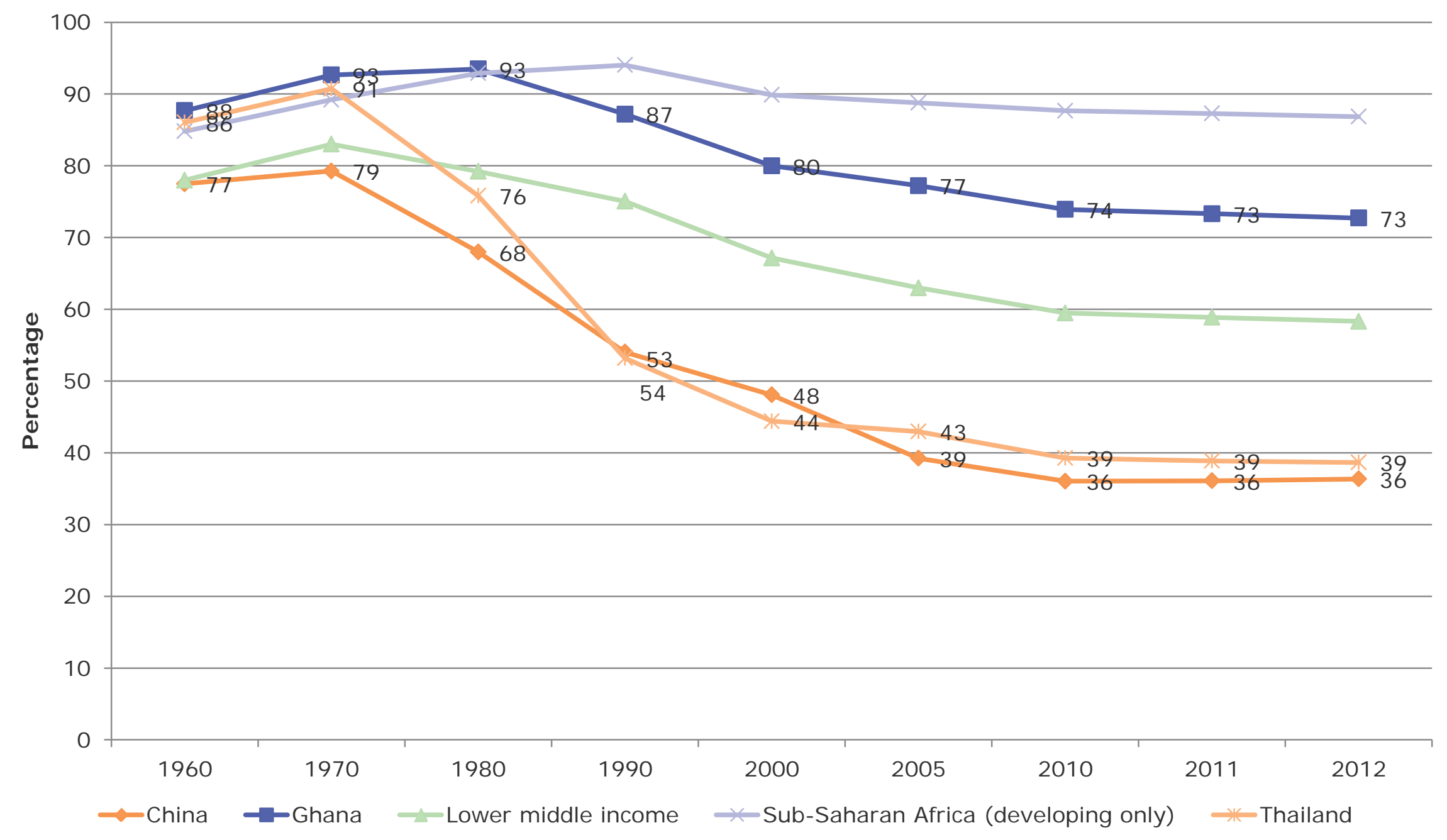




\section{Opportunities to Earn Dividend (4)}

\section{Total Fertility Rate}

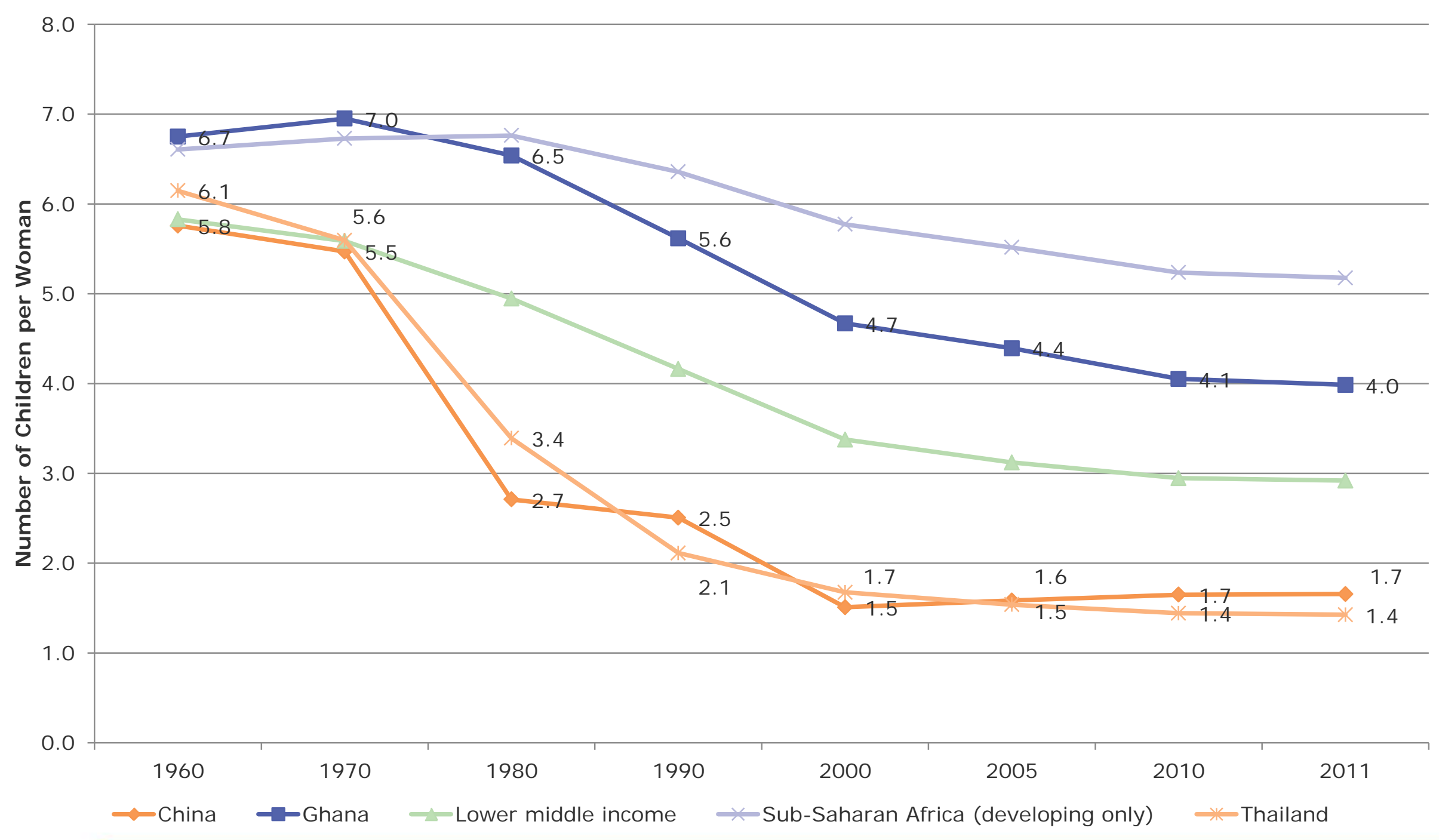




\section{What Should Governments do?}

- Invest in child survival and health programs.

- Commit to voluntary family planning to achieve the demographic transition.

- Invest in the reproductive health needs of both married and unmarried youth.

- Build human capital

- Prioritize education-especially secondary education for girls. 


\section{What can Governments do - Cont.}

- Stabilize the financial sector

- Encourage long term savings

- Improve transparency and governance 


\section{South - South Dialogue}

- Alliances to ensure contraceptive security

- Encouragement of open market and inter-country trade

- Technology transfer, capacity building and sharing of best practices

- Conducting and sharing research findings 


\section{Conclusion}

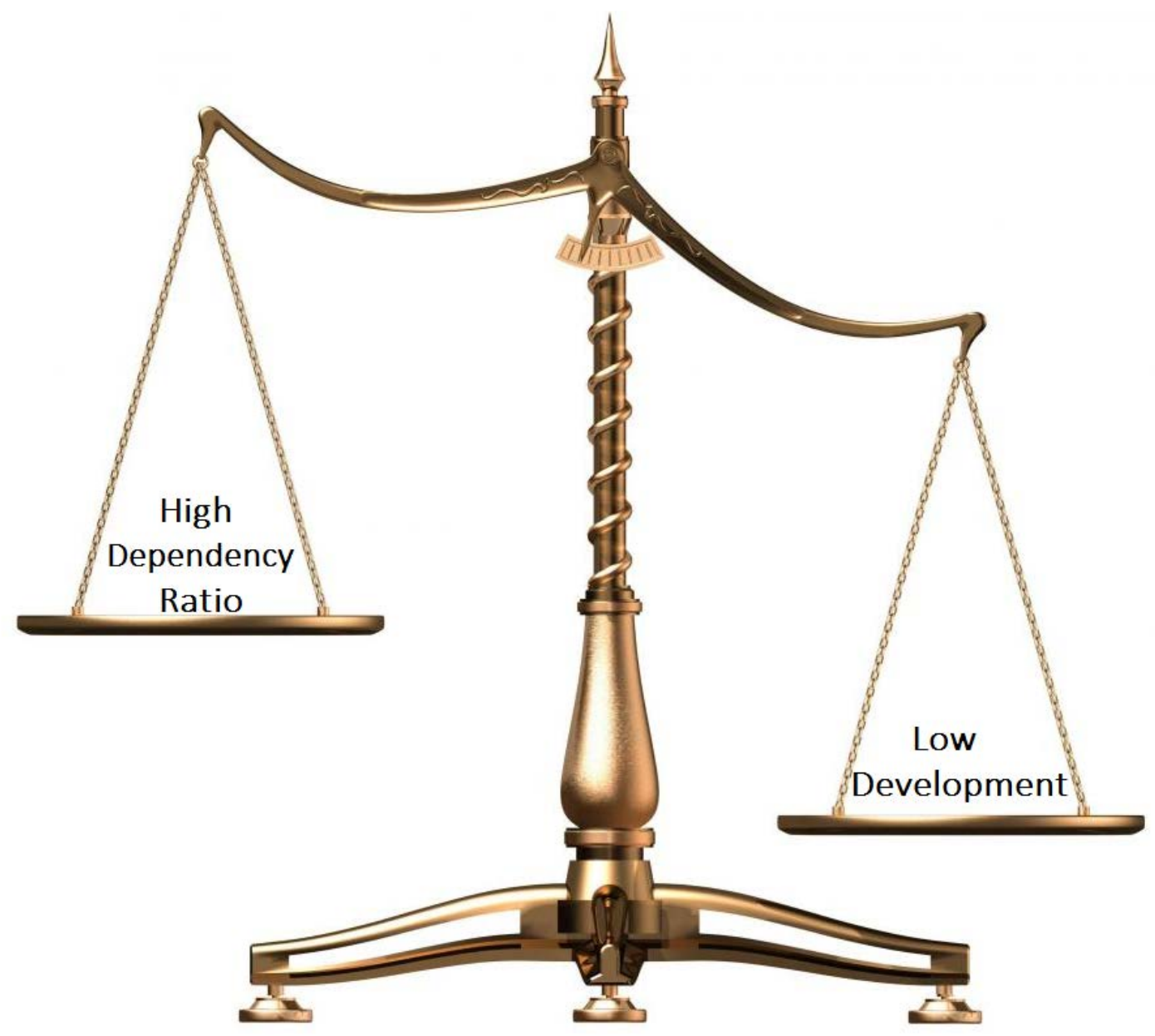


THANK YOU 